\title{
Rethinking the Economic Costs of Hospitalisation for Malaria: Accounting for the Comorbidities of Malaria Patients in Western Kenya
}

Caroline Watts ( $\sim$ cwatts@kirby.unsw.edu.au )

The Kirby Institute https://orcid.org/0000-0002-3811-4797

Harrysone Atieli

Maseno University

Jason Alacapa

Johns Hopkins University

Ming-Chieh Lee

University of California Irvine

Guofa Zhou

University of California Irvine

Andrew Githeko

Kenya Medical Research Institute

Guiyun Yan

University of California Irvine

\section{Virginia Wiseman}

London School of Hygiene \& Tropical Medicine

\section{Research}

Keywords: malaria, coinfection, healthcare costs, Kenya, Africa

Posted Date: June 4th, 2021

DOI: https://doi.org/10.21203/rs.3.rs-561893/v1

License: (1) This work is licensed under a Creative Commons Attribution 4.0 International License. Read Full License 


\section{Abstract}

\section{Background}

Malaria causes significant mortality and morbidity in sub-Saharan Africa, especially among children under five years of age and places a huge economic burden on individuals and health systems. While this burden has been assessed previously, few studies have explored how malaria comorbidities affect inpatient costs. This study in a malaria endemic area in Western Kenya, assessed the total treatment costs per malaria episode including comorbidities in children and adults.

Methods

Total economic costs of malaria hospitalisations were calculated from a health system and societal perspective. Patient-level data were collected from patients admitted with a malaria diagnosis to a county-level hospital between June 2016 and May 2017. All treatment documented in medical records were included as health system costs. Patient and household costs included direct medical and non-medical expenses, and indirect costs due to productivity losses.

Results

Of the 746 patients admitted with a malaria diagnosis, $64 \%$ were female and $36 \%$ were male. The mean age was 14 years (median 7 years). The mean length of stay was three days. The mean health system cost per patient was Kenyan Shilling (KSh) 4,288 (USD 42.0) (95\% confidence interval (Cl) 95\%Cl KSh 4,046-4,531). The total household cost per patient was KSh 1,676 (USD 16.4) (95\% Cl KSh 1,488-1,864) and consisted of: KSh 161 (USD1.6) medical costs; KSh 728 (USD 7.1) non-medical costs; and KSh 787 (USD 7.7) indirect costs. The total societal cost (health system and household costs) per patient was KSh 5,964 (USD 58.4) (95\%Cl KSh $5,534-6,394)$. Almost a quarter of patients $(24 \%)$ had a reported comorbidity. The most common malaria comorbidities were chest infections, diarrhoea, and anaemia. The inclusion of comorbidities compared to patients with-out comorbidities led to a $46 \%$ increase in societal costs (i.e. health system costs increased by $43 \%$ and patient and household costs increased by $54 \%$ ).

Conclusions

The economic burden of malaria is increased by comorbidities which are associated with longer hospital stays and higher medical costs to patients and the health system. Understanding the full economic burden of malaria is critical if future malaria control interventions are to protect access to care, especially by the poor.

\section{Background}

While there has been a worldwide decline in the number of cases and deaths over the last decade, malaria control strategies continue to place a significant economic burden on many resource-constrained health systems, especially those in sub-Saharan Africa.[1] Annually in Kenya, there are an estimated 3.5 million cases diagnosed and 10,700 deaths from malaria with the highest mortality rates in Western Kenya.[2] Kenya has had a national strategy in place since 2004 with guidelines for vector control, malaria management in pregnancy, and strategies to improve diagnosis and treatment.[3] Many endemic countries like Kenya also face 
increasing malaria incidence due to changing climatic and farming practices, particularly deforestation[4] as well as resistance to pyrethroid insecticides the main component found in treated bed nets and indoor household sprays.[5]

In Kenya, malaria is the most common reason for presentation at local hospitals,[6] and together with diarrhoea and pneumonia are the most common causes of death in infants under five years.[7] Decisions about seeking healthcare are often related to the perceived degree of morbidity risk $[8,9]$ and hence, it is not unusual for patients to present to hospital for treatment with more than one underlying condition.[10, 11] Some conditions such as anaemia (which is included in the national strategy for malaria control), are known to be associated with both malaria and helminth infections.[12,13] Studies examining the co-endemicity of these infections have found that increased worm burden infection is associated with increased malaria parasitaemia.[12,13] Other conditions, such as respiratory infections share similar symptoms to malaria, making it difficult to differentiate the cause of illness and can cause delays in seeking treatment as a respiratory infection may be expected to resolve without treatment.[14] Antibiotic use associated with diagnostic-confirmed malaria remains common. [15] Children presenting with malaria and gastrointestinal symptoms such as diarrhoea have been found to have significantly longer hospital stays than those who did not (3.13 \pm 1.78 versus $2.66 \pm 1.38$ days)[16] and influenza has been shown to increase hospital stays by $1-3$ days in settings where the typical stay was $3-5$ days [17].

The economic burden of malaria inpatient and outpatient care has been well-researched, and studies on household costs have found malaria imposes significant financial burden on households.[18, 19] However, few studies in Kenya have examined the extent to which such comorbidities affect the cost of malaria treatment. [20] Ensuring affordable malaria treatment is a stated priority in Kenya's Malaria Operational Plan,[3] and health promotion messages advise patients to promptly seek confirmatory testing and use artemisinin-based combination therapy (ACT) if malaria is diagnosed.[21] The United Nations Sustainable Goals[22] note that infants and young children are more likely to be affected by malaria, and hence these families will experience greater financial burden when caregivers must take time away from paid and unpaid activities when their children are ill. [15,23] Excluding costs of malaria comorbidities, may underestimate the actual cost of malaria related hospitalisations[24] and mask the financial burden experienced by patients and their families[25-27]. This study assessed the comorbidities associated with malaria and their impact on hospitalisations costs, from a health system and societal perspective.

\section{Methods}

\section{Study setting}

This study used patient-level data from Iguhu hospital, a sub-county hospital in Kakamega county, in the malaria endemic-prone Western Kenya highlands. The hospital is funded by the Kaka mega County government Health serving a population of 17,860 people. It has 21 beds and 4 cots catering for children, women, and men. Critically ill patients are transferred to Kakamega County Teaching and Referral Hospital in Kakamega township 16 kilometres away. The majority of the population work in small-scale subsistence farming keeping livestock, growing corn and tea or work in the informal sector. [28] Water catchments are used for agricultural purposes. Comprising both endemic and highland-epidemic prone areas, the topography, 
climate and farming methods favour high rates of malaria transmission.[29] A sample of children in Kakamega county found levels of parasitemia in Kakamega to be $33 \%$, well above the national average of $8 \%$. [30]

\section{Study sample}

The sample comprised all infants, children and adults admitted with a confirmed laboratory diagnosis of malaria to Iguhu hospital between June 2016 and May 2017.

\section{Cost data collection}

An ingredients-based approach[31] was used to estimate the health system and household costs of diagnosing and managing malaria hospitalisations. Patient and household costs were classified as: 1) direct costs (or out-of-pocket costs) subdivided into medical and non-medical costs; and 2) indirect costs. Direct medical costs included payments for hospital fees, medications and non-medical costs such as transport, meals and the costs of funerals for malaria related deaths. Indirect costs - including lost productive time due to travelling to hospital, being ill or providing care to a sick child - were estimated for adults over the age of 18 years using the human capital approach,[32] taking a subsistence wage for an agricultural worker [33] and multiplying it by the lost time.

\section{Measures}

To estimate resource use, detailed data were collected from hospital admission records which included: patient age, sex, village of residence, sublocation, pregnancy status, type of malaria diagnostic test conducted, type of malaria treatment, any other diagnostic tests and treatments, length of stay, discharge destination; and any fees paid by patients for their inpatient stay. Key personnel from Iguhu hospital advised on specific costs for patients, including hospital charges, transport and food, provision and stockouts of medications in the past 12 months, and the approximate costs of these medications at local village vendors.

\section{Health system costs}

Health system cost data were extracted from patient-level medical records and included costs associated with hospitalisation (bed cost), laboratory tests, medications and related overheads (S.Table 1). Health system costs were classified into four categories: bed day cost and a diagnostic test for malaria on admission, management of malaria, management of comorbidities such as diarrhoea and anaemia excluding antibiotics; and antibiotics for management of infection.

\section{Bed cost}

Inpatient cost per bed day was obtained from World Health Organization (WHO) "choosing interventions that are cost-effective (WHO-CHOICE)" framework. [34] These country-specific estimates are based on a primary level hospital with few specialties and between 30-200 beds and include all personnel, capital and accommodation costs excluding medications and tests. The cost per inpatient day was inflated to 2020 prices and averaged over 12 months.[35] This bed cost was multiplied by length of stay which was extracted from inpatient records. 


\section{Laboratory test for malaria}

All inpatients had confirmed malaria and the cost of microscopic diagnosis was derived from previously published estimates for Kenya.[20]

\section{Medications for management of malaria and additional treatment}

As the hospital records only listed the names of medications, dosage calculations were based on recommended dosage and duration documented in the Médecins Sans Frontières (MSF) Essential Drugs,[36] and MSF Clinical Guidelines[37] based on diagnosis. When recommended dosages were based on a child's weight, approximate weights for age were calculated using the WHO weight for age charts[38] and costs were estimated based on manufacturer formulations and pack size. Dosages were independently calculated by $\mathrm{CW}$ and JA. When an antibiotic was recorded but an additional diagnosis was not documented (10\% cases), the most frequent diagnosis for persons of a similar age in the dataset who were also prescribed that antibiotic was used to estimate dosage.

The costs of medications and equipment were estimated using the Kenya Medical Supplies Authority (KEMSA) price list.[39] KEMSA is funded through the Ministry of Health and is responsible for the procurement and sales of essential medicines and medical supplies to government health facilities. For drugs not included on the KEMSA list, a mean cost was calculated using the Kenya Drug-Index.[40] The costs of microscopy to detect parasites in blood samples used to confirm a diagnosis of malaria were based on previously published estimates.[20]

All medications listed in the hospital records and administration costs (disposable needles and syringes, IV giving sets) were included. For an additional diagnosis of dehydration, the cost for the insertion of an intravenous line and 24 hours of IV fluids was included. For anaemia, where blood was required, it was assumed that one unit of packed cells was used[41] and that any oral supplements prescribed were administered for the duration of inpatient stay.

\section{Patient and household costs}

\section{Direct medical costs}

Direct patient costs included: registration books, laboratory test for malaria on admission and any hospital fees documented in hospital records. Children under five years of age and pregnant women were exempted from paying a registration fee and fees for malaria laboratory tests. Hospital inpatient charges to patients were included as recorded in the patient record. Any inpatient charges were assumed to be paid at discharge and deducted from the total health system cost.

Costs for medication following discharge were based on prices in the Iguhu hospital pharmacy medications price manual.[42] Hospitals set their own price for medications dispensed to discharged patients and outpatients. If the drug was not listed in the manual, the price in the KEMSA price list was doubled to reflect the price ratio in the pharmacy manual.

\section{Direct non-medical costs}


Travel costs of patients and any accompanying persons were estimated for motorbike taxi transport. If the patient was a child under 6 years of age it was assumed that a caregiver travelled to and from the hospital with them and a meal was purchased each day. If a patient had to be transferred to Kakamega, an additional cost was estimated for a return trip. In the case of death, funeral costs were also included.

Discounting was not necessary as all costs were estimated over one year. Any costs from the published literature were converted to local currency (Kenyan Shilling) and adjusted for inflation to 2020. Changes over time in the prices of non-medical goods and services were adjusted using the Kenya consumer price index (CPI) [35], and medical costs were adjusted using the Kenyan CPI for Health [43], and then converted to USD. [44]

\section{Statistical analysis}

Patient-level data were transferred securely in a Microsoft Excel format and analysis was performed using SAS 9.4 (SAS Institute, Cary NC). Patient characteristics are described with chi-square tests used to calculate differences in proportions. Sensitivity analysis was conducted to examine the impact on household costs of an increase in hospital costs due to inflation (5\%); and the impact of stockouts of antibiotics as this was reported to be a common issue by hospital personnel. If antibiotics were not available from the hospital, it was assumed they would be purchased from a local vendor. The percentage difference between the public sector (hospitals) and private sector (pharmacies) procurement prices for locally produced and imported medicines (expressed as median price ratios) [45] was used to estimate the cost increase in antibiotics if they were purchased from a local vendor. To reflect usual availability of medicines, the proportion of imported medicines (55\%) and locally produced medicines (45\%) were also taken into account. [45] Based on these assumptions, the price of antibiotics in the private sector was estimated to be $158 \%$ higher than in the public sector. It was assumed antibiotics were in stock $66 \%$ of the time based on the reported availability of general medicines in the public sector.[45]

\section{Results}

The sample consisted of 746 inpatients, 478 (64\%) females and 268 (36\%) males. The mean age for patients was 14.5 years, median 7 years (IQR 2.5-21). The median age for females was 11 years (IQR 3.4-30 years) and males 4 years (IQR: 2-9). There were 41 women admitted to hospital who were pregnant. Most patients (98\%) were discharged home, with 7 (1\%) patient deaths and 9 (1\%) hospital transfers (Table 1). Almost all individuals (98\%) admitted to hospital were diagnosed with severe malaria. Intravenous Artesunate was given to $98 \%$ of patients, with the remaining patients $(2 \%)$ receiving Quinine (intravenous or oral) or oral Artesunate.

Of the patients admitted, 179 (24\%) had a documented comorbidity in addition to malaria. Younger patients ( $<5$ years) were more likely to have comorbidities compared to older patients $(p=0.02)(S$. Table S2). Patients with one or more comorbidities were more likely to stay longer than three days $(p<0.001)$. Gender was not associated with a reported comorbidity (Table S1). Of the comorbidities reported within this patient group, 22\% (38/171) were diarrhoea, 16\% (27/171) upper respiratory tract infection, 15\% (26/171) anaemia, and 14\% (24/171) pneumonia (S. Table 3). Antibiotic use was documented for $61 \%$ (104/171) of patients and was generally consistent across all groups, ranging from $13 \%$ of inpatients in the $5 \leq 12$ years and $>12$ years age groups to $16 \%$ of children up to 5 years. 
Of this patient group, 614 patients (82\%) incurred some direct costs. These included 167 patients who only paid registration or laboratory costs $(27 \%)$ and 229 patients (37\%) who paid a hospital inpatient fee of KSh 100 (USD 1). Both of these fees were paid by 209 patients (34\%) and nine patients (2\%) paid higher fees between KSh 200-KSh 850. (S. Table 3). Five pregnant women paid a hospital inpatient fee.

The mean health system cost was Kenyan Shilling (KSh) 4,288 (USD 42.0) (95\% confidence interval (Cl) 95\%Cl KSh 4,046-4,531). Total patient and household costs averaged KSh 1,676 (USD 16.4) (95\%Cl KSh 1,488-1,864) per patient, consisting of KSh 161 (USD1.6) medical and KSh 728 (USD 7.1) non-medical costs and KSh 787 (USD 7.7) indirect costs. The total societal cost (health system and household costs) was KSh 5,964 (USD 58.4) $(95 \% \mathrm{Cl} \mathrm{KSh} 5,534-6,394)$ (Table 2).

\section{Accounting for additional illness}

Almost a quarter of patients $(24 \%)$ had an additional reported diagnosis. If patients with no comorbidities were compared to patients experiencing one or more comorbidities, mean health system costs per patient increased by $43 \%$ from KSh 3,877 (USD 38.0) to KSh 5,538 (USD 54.3) respectively. Total mean patient and household costs increased by $54 \%$ from KSh 1,480 (USD 14.5) to KSh 2,281 (USD 22.4), of which direct costs increased by $80 \%$ from KSh 743 (USD 7.3) to KSh 1,337 (USD 13.1), and indirect costs due to productivity losses increased by 22\% from KSh 737 (USD 7.2) to KSh 945 (USD 9.3) (Figure 1, Table 2). Societal costs were $46 \%$ higher for admissions with at least one comorbidity in addition to malaria, compared to malaria only diagnoses (Figure 1, Table 2).

Overall, $27 \%$ of patients were in hospital longer than the average length of stay of three days. If patients who were in hospital for three days or less, were compared with patients who stayed longer than three days, health system costs were $47 \%$ higher, increasing from KSh 3,468 (USD 34.0) to KSh 6,560 (USD 64.3). Total mean patient and household costs increased by $57 \%$ from KSh 1,456 (USD 14.3) to KSh 2,283 (USD 22.4) of which direct costs increased by $29 \%$ from KSh 825 (USD 8.1) to KSh 1,062 (USD 10.4) per patient and productivity losses increased by 48\% from KSh 631 (USD 6.2) to KSh 1,220 (USD 12.0) per patient (Figure 1, Table 2). Societal costs were $80 \%$ higher for patients who had longer than average stays in hospital compared to patients who stayed three days or less in hospital (Figure 1, Table 2).

\section{Sensitivity analysis}

Based on all patients (Table 2), a $5 \%$ increase in hospital and medicine costs increased societal costs by $4 \%$ to KSH 6,186 (USD 60.6). Antibiotics availability in hospitals $66 \%$ of the time would decrease health system costs by $0.4 \%$ to KSh 4,272 (USD 41.9 ) and increase total patient and household costs by $7 \%$ to KSh 1,797 (USD 17.6), due to the $14 \%$ increase in direct medical costs which increased from KSh 889 (USD 8) to KSH 1,010 (USD 9.9). Overall, the societal cost was increased by $2 \%$ to KSh 6,102 (USD 59.7) (S. Table 4). Antibiotics availability in hospitals $10 \%-34 \%$ of the time would increase total patient and household costs by $11 \%-9 \%$ respectively (S. Table 4).

\section{Discussion}


The costs associated with a visit to hospital for malaria represent a significant cost to the Kenyan health care system and to patients in malaria-endemic areas such as Iguhu. Almost a quarter of patients admitted with malaria had at least one additional illness. While the inclusion of additional treatment provided during a hospital stay for malaria increased total health system costs the impact was greatest on household costs. Additional direct medical costs were incurred for medications and hospital inpatient fees and non-medical costs for transport and food. Transportation costs were found to be a key driver of direct patient costs, as reported in several other studies, $[46,47]$. The additional cost for a hospital admission of USD 7 to patients and their households is significant, given that the average income in Kenya is less than USD 3 a day.

Our data aligns with other studies examining inpatient costs of malaria treatment. [18] [48] [49] [50] The mean patient cost of USD 15.5 for an average length of three days stay is similar to Kodhiambo's et al [18] estimate of USD 10 for two days stay which was obtained from parent surveys for children with a malaria diagnosis admitted to multiple level (Level II to Level V) health facilities. The proportions of total household costs for direct medical and non-medical costs and indirect costs are quite similar between the two studies.[18] These results are also consistent with healthcare spending patterns described by Barasa et al [46] who used the Kenya Household Expenditure and Utilization Survey and found that transport costs constituted one-third of direct inpatient costs, and also that for poorer households with limited disposable income, such costs could reduce household consumption and potentially have an impoverishing effect. [46] Household costs have also been found to increase where levels of endemicity are highest but the incremental effect of comorbidities on costs was not investigated.[23] Our findings also align with Sicuri et al's [49] estimates of health system and direct household costs for a hospital malaria admission without a comorbidity, however, their indirect costs are three times higher due to the inclusion of lifelong productivity losses [49], highlighting the economic impact of premature death. A study from Kenya that separated the cost of management of malaria from comorbidities, found that the addition of pneumonia increased the health system cost of hospitalisation by 13\%.[50] The overall health system costs for paediatric admissions in a Level IV hospital ranged from USD 47.2 to USD 75.2 in 2005, largely due to bed day costs and were much higher compared to this study.[50]

There were a few limitations with this analysis. Firstly, costs may have been underestimated. Inpatient laboratory tests were not documented and therefore not included in this cost analysis, but we assume these costs would be minimal given this was a Level 3 hospital. We also did not include costs for patients who were transferred as we were unable to follow their care or outcomes. Costs may have also been missed if medications or additional medical conditions were not recorded by staff at the time of admission or discharge. Information about prior health-seeking behaviour such as whether patients had presented on another day and been sent home, or if any other medications had been purchased prior to presenting at the hospital was not available. Secondly, shortages of general medicines in public hospitals in Kenya is not unusual [45], and was only examined in the sensitivity analysis based on general medicine shortages, rather than antibiotics which typically have lower availability [45], and hence, we may have underestimated patient out-of-pocket costs associated with purchasing these medicine in the private retail sector. The use of hospital patient records, the hospital pharmacy medications and price list, and the KEMSA procurement pricelist meant that accurate data was obtained, avoiding recall bias which is sometimes an issue using household surveys to estimate costs.[51, 52] Thirdly, we may have underestimated reductions in productivity due to additional days not working at full capacity as it is likely that caregivers would have reduced capacity to work while also caring for children 
recuperating at home. $[19,53]$ And finally, as noted in the preceding paragraph this valuation did not include costs associated with lifelong productivity loss due to death from malaria.

Despite health financing reforms that have removed user fees in public primary health facilities and provided free maternity care,[54] $82 \%$ of patients in this study admitted with malaria incurred a hospital fee which included $12 \%$ of pregnant women and around $30 \%$ of children aged under five years. Hospital fees were also reported in an earlier study of out-of-pocket costs for children aged under five years in Kenya [55] indicating hospital charges are still occurring in public health facilities. In this study, hospital fees were on average slightly lower for patients with a comorbidity or with longer lengths of stay compared to the average patient, indicating some internal censoring of fees charged to patients, and that a portion of the fees may be waivered for some patients who are more ill. Regardless, a comorbidity or longer length of stay meant that households incurred higher out-of-pocket costs for transport, food, and medicines.

\section{Conclusion}

Although the economic burden of malaria in Kenya has been assessed previously, most studies did not capture costs beyond the treatment of malaria and malaria sequalae. Comorbidities such as anaemia, diarrhoea and infections are common and increase treatment costs and length of stay, however the extent of this burden on the health system and households remains unclear. Further research is required to understand the true cost of a hospital admission for malaria in a range of malaria-endemic areas. Evidence on the aggregate inpatient costs of malaria and its comorbidities is important for designing interventions to improve access to treatment especially by the poor, and for conducting economic evaluations of these interventions.

\section{Abbreviations}

$\mathrm{Cl}$ confidence interval

CPI consumer price index

IQR inter quartile range

KEMSA Kenya Medical Supplies Authority

KSh Kenyan Shilling

MSF Médecins Sans Frontières

USD US dollar

WHO World Health Organization

\section{Declarations}

Ethics approval and consent to participate 
The study was approved by the Ethical Review Board of Kenya Medical Research Institute (SSC protocol No3005) and county authority to access hospital records in Iguhu hospital. Individual patient consent was not sought, and identifying information was not collected.

Consent for publication

Not applicable

Availability of data and material

The datasets generated during and/or analysed during the current study are not publicly available due to them containing information that could compromise research participant privacy/consent, but are available from the corresponding author on reasonable request.

Competing interests

The authors declare that they have no competing interests

Funding

This work was supported by Grants from the National Institutes of Health (R01 Al050243, and D43 TW001505).

Authors' contributions

CW and VW conceived the study. The data was collated and assembled by HA, MCL and GZ. CW analysed and interpreted the inpatient data. Dosages were independently calculated by CW and JA. All authors wrote and approved the final manuscript.

Acknowledgements

Brian Musalia, Alex Machanga, and the Iguhu hospital staff for their assistance with data collection.

\section{References}

1. WHO: WHO Global Malaria Programme World Malaria Report. Geneva Switzerland: WHO Press, World Health Organization; 2015.

\section{CDC's Global Malaria Activities}

[https://www.cdc.gov/malaria/malaria_worldwide/cdc_activities/index.html]

3. U.S Agency for International Development: President's Malaria Initiative (Kenya). In Malaria Operational Plan FY 2019. Washington USA: U.S Centrers for Disease Control and Prevention (CDC), U.S Department of heallth and Human Services (HHS); 2018.

4. Zhou G, Wiseman V, Atieli HE, Lee MC, Githeko AK, Yan G: The impact of long-lasting microbial larvicides in reducing malaria transmission and clinical malaria incidence: study protocol for a cluster randomized controlled trial. Trials 2016, 17:423. 
5. Zhou G, Afrane YA, Vardo-Zalik AM, Atieli H, Zhong D, Wamae P, Himeidan YE, Minakawa N, Githeko AK, Yan G: Changing Patterns of Malaria Epidemiology between 2002 and 2010 in Western Kenya: The Fall and Rise of Malaria.PLOS ONE 2011, 6:e20318.

6. Kapesa A, Kweka EJ, Atieli H, Afrane YA, Kamugisha E, Lee MC, Zhou G, Githeko AK, Yan G: The current malaria morbidity and mortality in different transmission settings in Western Kenya.PLOS One 2018, 13:e0202031.

7. World Health Organization: World Malaria Report 2018. Geneva Licence: CC BY-NC-SA 3.0 IGO.2018.

8. Etiaba E, Onwujekwe O, Uzochukwu B, Uguru N, Okoronkwo I, Adjagba A: What co-morbidities do people with malaria have and what are their patterns of health seeking in Nigeria?Niger J Clin Pract 2015, 18:2226.

9. Burton DC, Flannery B, Onyango B, Larson C, Alaii J, Zhang X, Hamel MJ, Breiman RF, Feikin DR: Healthcare-seeking behaviour for common infectious disease-related illnesses in rural Kenya: a community-based house-to-house survey.Journal of health, population, and nutrition 2011, 29:61-70.

10. D'Acremont V, Kilowoko M, Kyungu E, Philipina S, Sangu W, Kahama-Maro J, Lengeler C, Cherpillod P, Kaiser L, Genton B: Beyond Malaria - Causes of Fever in Outpatient Tanzanian Children.New England Journal of Medicine 2014, 370:809-817.

11. Feikin DR, Olack B, Bigogo GM, Audi A, Cosmas L, Aura B, Burke H, Njenga MK, Williamson J, Breiman RF: The burden of common infectious disease syndromes at the clinic and household level from populationbased surveillance in rural and urban Kenya.PLoS One 2011, 6:e16085.

12. Mulu A, Legesse M, Erko B, Belyhun Y, Nugussie D, Shimelis T, Kassu A, Elias D, Moges B: Epidemiological and clinical correlates of malaria-helminth co-infections in Southern Ethiopia.Malar J 2013, 12:227.

13. Degarege A, Veledar E, Degarege D, Erko B, Nacher M, Madhivanan P: Plasmodium falciparum and soiltransmitted helminth co-infections among children in sub-Saharan Africa: a systematic review and metaanalysis. Parasit Vectors 2016, 9:344.

14. Hercik C, Cosmas L, Mogeni OD, Kohi W, Mfinanga S, Loffredo C, Montgomery JM: Health Beliefs and Patient Perspectives of Febrile Illness in Kilombero, Tanzania.Am J Trop Med Hyg 2019, 101:263-270.

15. Hopkins H, Bruxvoort KJ, Cairns ME, Chandler CIR, Leurent B, Ansah EK, Baiden F, Baltzell KA, Björkman A, Burchett HED, et al: Impact of introduction of rapid diagnostic tests for malaria on antibiotic prescribing: analysis of observational and randomised studies in public and private healthcare settings.BMJ 2017, 356:j1054.

16. Lo Vecchio A, Basile FW, Bruzzese D, Di Dato F, Aol P, Omona V, Smarrazzo A, Guarino A: Diarrhea in Children with Plasmodium falciparum Malaria: A Case?Control Study on the Prevalence and Response to Antimalarial Treatment. The American Journal of Tropical Medicine and Hygiene 2021, 104:659-665.

17. Thompson MG, Breiman RF, Hamel MJ, Desai M, Emukule G, Khagayi S, Shay DK, Morales K, Kariuki S, Bigogo GM, et al: Influenza and Malaria Coinfection Among Young Children in Western Kenya, 20092011. The Journal of Infectious Diseases 2012, 206:1674-1684.

18. Kodhiambo MO, Oyugi JO, Amugune BK: Modelling the household cost of paediatric malaria treatment in a rural county in Kenya: do non-user fee payments matter? A partial cost of illness analysis.BMJ Open 2020, 10:e033192. 
19. Gunda R, Shamu S, Chimbari MJ, Mukaratirwa S: Economic burden of malaria on rural households in Gwanda district, Zimbabwe.African journal of primary health care \& family medicine 2017, 9:e1-e6.

20. Ayieko P, Akumu AO, Griffiths UK, English M: The economic burden of inpatient paediatric care in Kenya: household and provider costs for treatment of pneumonia, malaria and meningitis. Cost Effectiveness and Resource Allocation : C/E 2009, 7:3-3.

21. Kenya National Bureau of Statistics: Kenya Malaria Indicator Survey 2015. Nairobi Kenya: National Malaria Control Programme, ; 2016.

22. Sustainable development goals. [https://sdgintegration.undp.org]

23. Chuma J, Okungu V, Molyneux C: The economic costs of malaria in four Kenyan districts: do household costs differ by disease endemicity? Malar J 2010, 9:149.

24. Griffiths EC, Pedersen AB, Fenton A, Petchey OL: The nature and consequences of coinfection in humans. Journal of Infection 2011, 63:200-206.

25. Goodman CA, Coleman PG, Mills AJ: Cost-effectiveness of malaria control in sub-Saharan Africa.Lancet 1999, 354:378-385.

26. White MT, Conteh L, Cibulskis R, Ghani AC: Costs and cost-effectiveness of malaria control interventions a systematic review.Malaria Journal 2011, 10:337.

27. Haakenstad A, Harle AC, Tsakalos G, Micah AE, Tao T, Anjomshoa M, Cohen J, Fullman N, Hay SI, Mestrovic T, et al: Tracking spending on malaria by source in 106 countries, 2000-16: an economic modelling study.Lancet Infect Dis 2019, 19:703-716.

28. Wiesmann U, Kiteme, B., Mwangi, Z.: Socio-Economic Atlas of Kenya: Depicting the National Population Census by County and Sub-Location. Nairobi Kenya: KNBS, Nairobi. CETRAD, Nanyuki. CDE, Bern.; 2016.

29. National Malaria Control Programme (NMCP) Kenya National Bureau of Statistics (KNBS) and ICF International: 2015 Kenya Malaria Indicator Survey. Nairobi Kenya and Rockville Maryland USA: NMCP,KNBS and ICF International; 2016.

30. Bashir IM, Nyakoe N, van der Sande M: Targeting remaining pockets of malaria transmission in Kenya to hasten progress towards national elimination goals: an assessment of prevalence and risk factors in children from the Lake endemic region.Malaria Journal 2019, 18:233.

31. Chapko MK, Liu CF, Perkins M, Li YF, Fortney JC, Maciejewski ML: Equivalence of two healthcare costing methods: bottom-up and top-down.Health Econ 2009, 18:1188-1201.

32. Johannesson $\mathrm{M}$ : The willingness to pay for health changes, the human-capital approach and the external costs. Health Policy 1996, 36:231-244.

33. Minimum wages in kenya [https://mywage.org/kenya/salary/minimum-wage/]

34. Stenberg K, Lauer JA, Gkountouras G, Fitzpatrick C, Stanciole A: Econometric estimation of WHO-CHOICE country-specific costs for inpatient and outpatient health service delivery. Cost Eff Resour Alloc 2018, 16:11.

35. Kenya Consumer Price Index (CPI) and Inflation rates [http://www.knbs.or.ke/consumer-price-indice/]

36. Médecins Sans Frontières: Essential drugs - practical guidelines. In 2019 edition: ( Médecins Sans Frontières; 2019. 
37. Frontières. MS: Clinical guidelines - Diagnosis and treatment manual. In 2019 edition: (C) Médecins Sans Frontières; 2019.

38. Weight for age [https://www.who.int/childgrowth/standards/]

39. Kenya Essential Medicines List 2017 [http://www.kemsa.co.ke/salespricelist/]

40. Drug_Index.it The East African. 16th Edithion (2017/2018) edn. Nairobi Kenya: Pharmaceutical Loci Publishers; 2017.

41. A Blood Transfusion in Africa? It's Free in Rwanda, Unaffordable in Zimbabwe [https://globalpressjournal.com/africa/blood-transfusion-africa-free-rwanda-unaffordable-zimbabwe/]]

42. Iguhu Pharmacy Book. Iguhu Hospital2018.

43. Kenya CPI fo Health [https://www.statista.com/statistics/1165927/cpi-for-health-in-kenya/]

44. Official exchange rate (LCU per US\$, period average) [https://data.worldbank.org/indicator/PA.NUS.FCRF? year_high_desc=true]

45. Ewen.M, Okemo.DJ: Prices and Availability of Locally Produced and Imported Medicines in Kenya Survey Report July 2018. Amsterdam The Netherlands: Health Action International;; 2018.

46. Barasa EW, Maina T, Ravishankar N: Assessing the impoverishing effects, and factors associated with the incidence of catastrophic health care payments in Kenya.Int J Equity Health 2017, 16:31.

47. Njagi P, Arsenijevic J, Groot W: Understanding variations in catastrophic health expenditure, its underlying determinants and impoverishment in Sub-Saharan African countries: a scoping review.Systematic Reviews 2018, 7:136.

48. Chuma JM, Thiede M, Molyneux CS: Rethinking the economic costs of malaria at the household level: evidence from applying a new analytical framework in rural Kenya.Malar $\mathrm{J}$ 2006, 5:76.

49. Sicuri E, Vieta A, Lindner L, Constenla D, Sauboin C: The economic costs of malaria in children in three sub-Saharan countries: Ghana, Tanzania and Kenya.Malaria Journal 2013, 12:307.

50. Ayieko P, Akumu AO, Griffiths UK, English M: The economic burden of inpatient paediatric care in Kenya: household and provider costs for treatment of pneumonia, malaria and meningitis. Cost Eff Resour Alloc 2009, 7:3.

51. Adam T, Evans DB, Murray CJ: Econometric estimation of country-specific hospital costs. Cost Eff Resour Alloc 2003, 1:3.

52. Onwujekwe O, Uguru N, Etiaba E, Chikezie I, Uzochukwu B, Adjagba A: The economic burden of malaria on households and the health system in Enugu State southeast Nigeria.PLoS One 2013, 8:e78362.

53. Asenso-Okyere K, Asante FA, Tarekegn J, Andam KS: A review of the economic impact of malaria in agricultural development.Agricultural Economics 2011, 42:293-304.

54. The National Treasury and Planning, State department for planning, Monitoring and evaluation department: Comprehensive Public Expenditure Review From evidence to policy 2017. Nairobi, Kenya: Government of the Republic of Kenya; 2018.

55. Barasa EW, Ayieko P, Cleary S, English M: Out-of-pocket costs for paediatric admissions in district hospitals in Kenya.Trop Med Int Health 2012, 17:958-961.

\section{Tables}


Table 1. Characteristics of inpatients at Iguhu hospital $(n=746)$ 


\begin{tabular}{|c|c|}
\hline Characteristic & $\mathrm{n}(\%)$ \\
\hline \multicolumn{2}{|l|}{ Sex } \\
\hline Male & $268(36)$ \\
\hline Female & $478(64)$ \\
\hline \multicolumn{2}{|l|}{ Age group (years) } \\
\hline$\leq 5$ & $322(43)$ \\
\hline $5 \leq 12$ & $150(20)$ \\
\hline$>12$ & $274(37)$ \\
\hline \multicolumn{2}{|l|}{ Comorbidity } \\
\hline 0 & $567(76)$ \\
\hline 1 or more & $179(24)$ \\
\hline \multicolumn{2}{|l|}{ Length of stay (days) } \\
\hline 1 & $36(5)$ \\
\hline 2 & $189(25)$ \\
\hline 3 & $323(43)$ \\
\hline 4 & $100(13)$ \\
\hline 5 or more & $99(13)$ \\
\hline Mean length of stay (STD) & $3.1(1.3)$ \\
\hline \multicolumn{2}{|l|}{ Outcomes } \\
\hline Discharged home & $720(98)$ \\
\hline Transferred & $9(1)$ \\
\hline Deceased & $7(1)$ \\
\hline Missing & 10 \\
\hline \multicolumn{2}{|c|}{ Pregnancy status characteristics } \\
\hline Pregnant & 41 \\
\hline Mean weeks (min-max) & $28(17-35)$ \\
\hline
\end{tabular}

Page 15/ 19 
${ }^{1}$ Includes documented treatment respiratory tract infection, dehydration and diarrhoea or dehydration and parasites, aneamia

Table 2 Mean health system and patient costs related to hospitalisation with confirmed malaria diagnosis. 


\begin{tabular}{|c|c|c|c|c|c|c|c|c|c|c|}
\hline \multirow[t]{3}{*}{$\begin{array}{l}\text { Description } \\
\text { of cost }\end{array}$} & \multicolumn{2}{|c|}{ All patients } & \multicolumn{2}{|c|}{$\begin{array}{l}\text { Patients with } \\
\text { no comorbidity }\end{array}$} & \multicolumn{2}{|c|}{$\begin{array}{l}\text { Patients with } \\
\text { one of more } \\
\text { comorbidities }\end{array}$} & \multicolumn{2}{|c|}{$\begin{array}{l}\text { Hospital stay } \\
\leq 3 \text { days }\end{array}$} & \multicolumn{2}{|c|}{$\begin{array}{l}\text { Hospital stay > } \\
\text { 3days }\end{array}$} \\
\hline & \multicolumn{2}{|l|}{$n=746$} & \multicolumn{2}{|l|}{$n=570$} & \multicolumn{2}{|l|}{$n=176$} & \multicolumn{2}{|l|}{$n=547$} & \multicolumn{2}{|l|}{$\mathrm{n}=199$} \\
\hline & $\begin{array}{l}\text { Mean } \\
\text { cost }\end{array}$ & $95 \% \mathrm{Cl}$ & $\begin{array}{l}\text { Mean } \\
\text { cost }\end{array}$ & $95 \% \mathrm{Cl}$ & $\begin{array}{l}\text { Mean } \\
\text { cost }\end{array}$ & $95 \% \mathrm{Cl}$ & $\begin{array}{l}\text { Mean } \\
\text { cost }\end{array}$ & $95 \% \mathrm{Cl}$ & $\begin{array}{l}\text { Mean } \\
\text { cost }\end{array}$ & $95 \% \mathrm{Cl}$ \\
\hline \multicolumn{11}{|l|}{$\begin{array}{l}\text { Health } \\
\text { system cost }\end{array}$} \\
\hline $\begin{array}{l}\text { Hospital } \\
\text { admission } \\
\text { and bed cost }\end{array}$ & 2650 & $\begin{array}{l}2574- \\
2727\end{array}$ & 2552 & $\begin{array}{l}2474- \\
2631\end{array}$ & 2963 & $\begin{array}{l}2770- \\
3156\end{array}$ & 2145 & $\begin{array}{l}2101- \\
2188\end{array}$ & 4052 & $\begin{array}{l}3923- \\
4182\end{array}$ \\
\hline $\begin{array}{l}\text { Malaria } \\
\text { management }\end{array}$ & 1378 & $\begin{array}{l}1331- \\
1426\end{array}$ & 1324 & $\begin{array}{l}1277- \\
1372\end{array}$ & 1549 & $\begin{array}{l}1427- \\
1672\end{array}$ & 1137 & $\begin{array}{l}1104- \\
1170\end{array}$ & 2046 & $\begin{array}{l}1937- \\
2154\end{array}$ \\
\hline $\begin{array}{l}\text { Additional } \\
\text { treatment }^{1}\end{array}$ & 212 & $\begin{array}{l}109- \\
306\end{array}$ & 0 & - & 831 & $\begin{array}{l}408- \\
1253\end{array}$ & 158 & $\begin{array}{l}54- \\
262\end{array}$ & 363 & $\begin{array}{l}98- \\
628\end{array}$ \\
\hline Antibiotics & 47 & $32-62$ & 0 & - & 195 & $\begin{array}{l}137- \\
254\end{array}$ & 28 & $20-36$ & 100 & $\begin{array}{l}47- \\
152\end{array}$ \\
\hline $\begin{array}{l}\text { Total health } \\
\text { system cost }\end{array}$ & 4288 & $\begin{array}{l}4046- \\
4531\end{array}$ & 3877 & $\begin{array}{l}3800- \\
4053\end{array}$ & 5583 & $\begin{array}{l}4785- \\
6380\end{array}$ & 3468 & $\begin{array}{l}3393- \\
3639\end{array}$ & 6560 & $\begin{array}{l}6054- \\
7166\end{array}$ \\
\hline \multicolumn{11}{|l|}{$\begin{array}{l}\text { Household } \\
\text { costs }\end{array}$} \\
\hline \multicolumn{11}{|l|}{ Direct costs } \\
\hline \multicolumn{11}{|l|}{$\begin{array}{l}\text { Medical } \\
\text { costs }\end{array}$} \\
\hline $\begin{array}{l}\text { Registration, } \\
\text { hospital fee }\end{array}$ & 118 & $\begin{array}{l}111- \\
125\end{array}$ & 119 & $\begin{array}{l}111- \\
128\end{array}$ & 113 & $\begin{array}{l}103- \\
122\end{array}$ & 120 & $\begin{array}{l}113- \\
129\end{array}$ & 111 & $\begin{array}{l}100- \\
123\end{array}$ \\
\hline Antibiotics & 41 & $29-52$ & - & - & 166 & $\begin{array}{l}125- \\
201\end{array}$ & 42 & $28-56$ & 35 & $19-50$ \\
\hline $\begin{array}{l}\text { Other } \\
\text { medication }\end{array}$ & 2 & $1-3$ & - & - & 8 & $4-12$ & 2 & $1-3$ & 3 & $1-6$ \\
\hline \multicolumn{11}{|l|}{$\begin{array}{l}\text { Non-medical } \\
\text { costs }\end{array}$} \\
\hline $\begin{array}{l}\text { Transport \& } \\
\text { food cost }\end{array}$ & 599 & $\begin{array}{l}558- \\
640\end{array}$ & 551 & $\begin{array}{l}507- \\
495\end{array}$ & 741 & $\begin{array}{l}648- \\
834\end{array}$ & 511 & $\begin{array}{l}475- \\
547\end{array}$ & 844 & $\begin{array}{l}733- \\
955\end{array}$ \\
\hline $\begin{array}{l}\text { Funeral } \\
\text { costs }\end{array}$ & 129 & $\begin{array}{l}34- \\
225\end{array}$ & 73 & $0-155$ & 308 & $7-609$ & 151 & $\begin{array}{l}30- \\
271\end{array}$ & 70 & $0-207$ \\
\hline $\begin{array}{c}\text { Subtotal } \\
\text { direct costs }\end{array}$ & 889 & $\begin{array}{l}733- \\
1044\end{array}$ & 743 & $\begin{array}{l}608- \\
878\end{array}$ & 1337 & $\begin{array}{l}887- \\
1699\end{array}$ & 825 & $\begin{array}{l}647- \\
1005\end{array}$ & 1062 & $\begin{array}{l}785- \\
1339\end{array}$ \\
\hline
\end{tabular}




\begin{tabular}{|c|c|c|c|c|c|c|c|c|c|c|}
\hline $\begin{array}{l}\text { Productivity } \\
\text { loss }\end{array}$ & 787 & $\begin{array}{l}755- \\
1044\end{array}$ & 737 & $\begin{array}{l}703- \\
772\end{array}$ & 945 & $\begin{array}{l}822- \\
960\end{array}$ & 631 & $\begin{array}{l}601- \\
655\end{array}$ & 1220 & $\begin{array}{l}1149- \\
1291\end{array}$ \\
\hline $\begin{array}{l}\text { Total } \\
\text { household } \\
\text { costs }\end{array}$ & 1676 & $\begin{array}{l}1488- \\
1864\end{array}$ & 1480 & $\begin{array}{l}1311- \\
1650\end{array}$ & 2281 & $\begin{array}{l}1839- \\
2502\end{array}$ & 1456 & $\begin{array}{l}1252- \\
1660\end{array}$ & 2283 & $\begin{array}{l}1935- \\
2630\end{array}$ \\
\hline Total & 5964 & $\begin{array}{l}5534- \\
6394\end{array}$ & 5357 & $\begin{array}{l}5061- \\
5654\end{array}$ & 7820 & $\begin{array}{l}6500- \\
9139\end{array}$ & 4923 & $\begin{array}{l}4532- \\
5316\end{array}$ & 8843 & $\begin{array}{l}7940- \\
9746\end{array}$ \\
\hline
\end{tabular}

${ }^{1}$ Additional treatment relates to costs for management of comorbidities excluding costs of antibiotics.

\section{Figures}

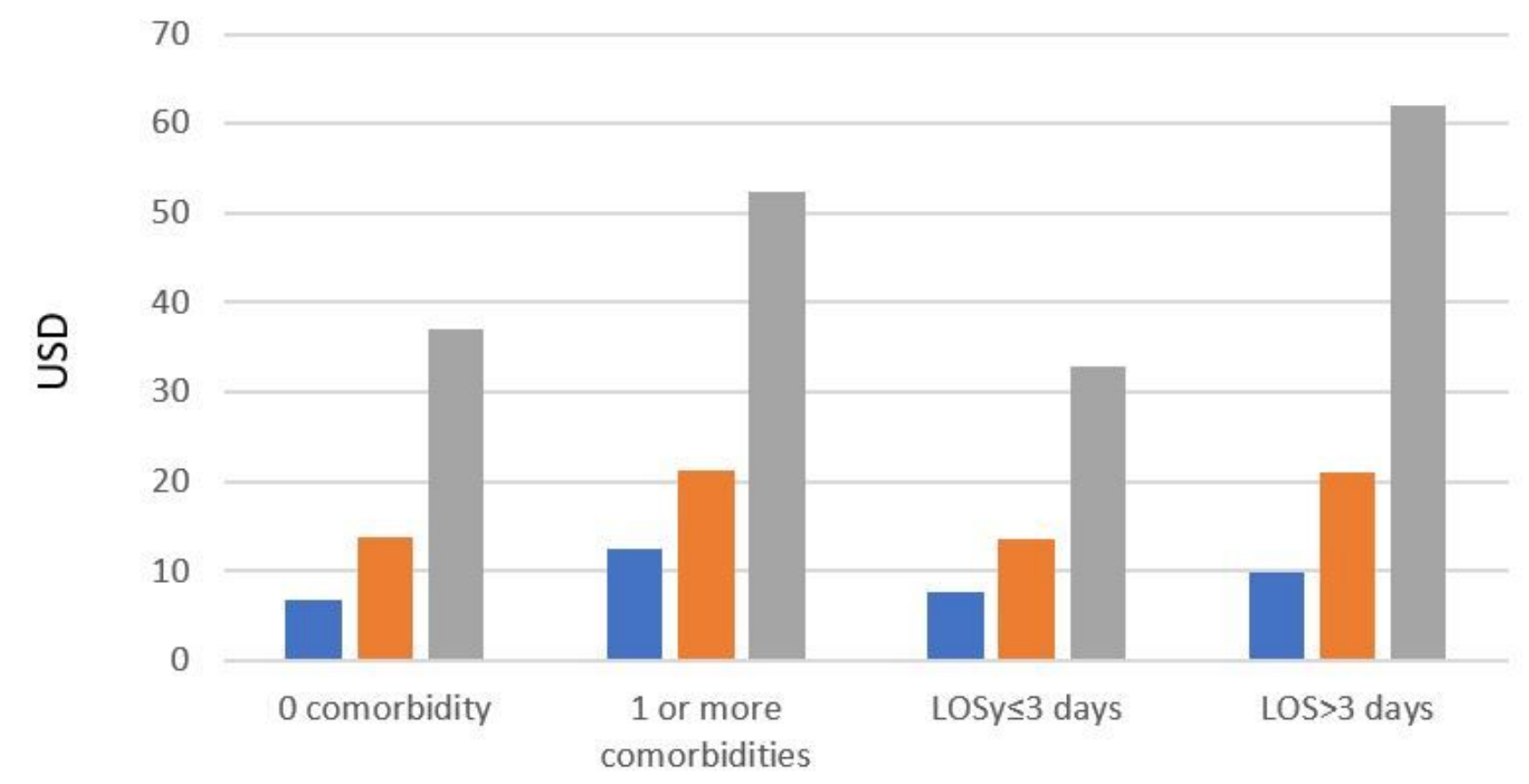

Out of pocket cost $\quad$ Patient cost $\quad$ Health system cost

\section{Abbreviation LOS Length of stay}

\section{Figure 1}

Bar chart showing difference in mean inpatient costs based on patient characteristics. 


\section{Supplementary Files}

This is a list of supplementary files associated with this preprint. Click to download.

- AdditionalmaterialsMalariaCostlguhu.docx 